\title{
FICTIVE INTERACTION AND THE NATURE OF LINGUISTIC MEANING*
}

\author{
Sergeiy Sandler \\ Forthcoming in: Esther Pascual and Sergeiy Sandler (eds), The conversation \\ frame: Forms and functions of fictive interaction. Amsterdam/Philadelphia: \\ John Benjamins
}

One may distinguish between three broad conceptions of linguistic meaning. One conception, which I will call "logical", views meaning as given in reference (for words) and truth (for sentences). Another conception, the "monological" one, seeks meaning in the cognitive capacities of the single mind. A third, "dialogical", conception attributes meaning to interaction between individuals and personal perspectives. In this chapter I directly contrast how well these three approaches deal with the evidence brought forth by fictive interaction. I examine instances of fictive interaction and argue that intersubjectivity in these instances cannot be reduced to either referential-logical or individual-cognitive semantic notions. It follows that intersubjectivity must belong to the essence of linguistic meaning.

Keywords: dialogism, intersubjectivity, philosophy of language, semantics, theories of meaning.

The conversation frame is a frame of intersubjectivity. In fictive interaction, the conversation frame, and thus intersubjectivity, emerges as the structure behind many linguistic and cognitive phenomena (Pascual 2002, 2006, 2014).

*Work for this chapter was supported by a Vidi research program (276.70.019, Principal Investigator: E. Pascual) from the Netherlands Organization for Scientific Research (NWO). I would like to thanks Esther Pascual and Karen Sullivan for many valuable comments on earlier drafts of the text. 
Thus, when a business offers its potential customers a "Not happy? Money back! guarantee" (Pascual 2014, p. 65), a scenario is being set up, in which a buyer exhibits dissatisfaction, the seller asks her: "Not happy?", she confirms, and, finally, the seller redresses her dissatisfaction by offering her money back. This entire conversation, only part of which is spelled out, modifies the noun "guarantee" and establishes a category, a kind of purchase arrangement (Pascual, Królak and Janssen 2013). Referring to this kind of guarantee and thinking of it thus involves intersubjectivity on the conceptual level.

So what? Yes, people use language to communicate, but centuries of philosophical and linguistic tradition tell us that, at least when we consider the nature of linguistic meaning, intersubjectivity and communication do not come first. In this chapter, I offer an argument for the opposite view. I examine instances of fictive interaction and argue that intersubjectivity in these instances cannot be reduced to allegedly "simpler" semantic notions. It follows that intersubjectivity must belong to the essence of linguistic meaning.

In making these claims, I will be applying a distinction between three different approaches to the nature of language and meaning. The distinction (made originally by Voloshinov 1986) is based on the number of people necessary for linguistic meaning to emerge.

One view-I will call it the logical approach-seeks meaning in the words and sentences of a given expression in-and-of-themselves, belonging 
to the abstract (logical) system of language. The minimum number of persons necessary for an expression to be meaningful on this view is zero.

A second view-I will call it the monological approach-seeks meaning in the mind (or cognitive capacities or conceptualizations) of the individual human being. The minimum number of people necessary for an expression to be meaningful on this view is thus one.

Finally, the third, dialogical approach seeks meaning in interaction between persons and sees language as structured through-and-through by such interaction. This approach requires a multiplicity of people (two or more) for an expression to be meaningful (and note that this is a multiplicity of individuals; an undifferentiated mass of "society" will not do).

In what follows, I present logical and monological responses to the phenomenon of fictive interaction, and will argue, based on the evidence fictive interaction brings, for a consistently dialogical approach.

\section{The logical approach to language}

Let me begin with a quote from the first chapter of Aristotle's $D e$ Interpretatione (Barnes 1984, p. 25):

Now spoken sounds are symbols of affections in the soul, and written marks symbols of spoken sounds. And just as written marks are not the same for all men, neither are spoken sounds. But what these are in the first place signs 
of - affections of the soul - are the same for all; and what these affections are likenesses of - actual things - are also the same [...] Just as some thoughts in the soul are neither true nor false while some are necessarily one or the other, so also with spoken sounds. For falsity and truth have to do with combination and separation. Thus names and verbs by themselves-for instance "man" or "white" when nothing further is added - are like the thoughts that are without combination and separation; for so far they are neither true nor false.

This passage offers us the earliest and most influential conceptualization of language, at least in Western culture (Arens 1984). It is a picture of language we all still easily recognize today: words signify concepts, which in turn stand for things in the world and their properties. If the word for a property is predicated of a word for an object that has this property, the result is a sentence expressing a true proposition. Absent such a match between words and reality, the proposition is false. The conditions for forming a sentence are defined by truth and falsity.

Note that in this picture, meaning resides in words, their combination, and their connection with things. Human beings are part of the process (through the "affections of the soul"), but their role is entirely passive (these affections are copies of forms in the world, not shaped by the soul that bears them). Note also the role of logic ("truth and falsity") in this account.

Aristotle's conceptualization of language gave us the grammar taught in grammar school, it gave us the units into which we break language down, it created the terrain on which millennia of philosophical and linguistic battles 
on the word-concept-object axis were waged. More recently, the entire Fregean tradition in the philosophy of language (including formal semantics and indeed also Generativism in linguistics) can be seen as an extended elaboration on the theme of "falsity and truth have to do with combination and separation". Aristotle's picture is so deeply ingrained in the way we look at language that we'd be naïve to think, even today, that we have overcome it.

And yet, for some decades now, we have seen evidence amass that shows this picture is deeply misleading. Central elements of it came under direct attack from cognitive linguists (e.g. Fauconnier 1990; Fauconnier and Turner 2002; Langacker 1987), functional linguists (e.g. Hopper 1998), discourse and conversation analysts and interactionists (e.g. Ochs, Schegloff, \& Thompson 1996) and others. Unfortunately, space does not allow me to review this evidence and arguments based on it, but I do want to briefly examine one particular kind of critique. This critique, unlike others, received considerable attention from logically-minded linguists and philosophers (e.g., Gendler Szabó 2005), which also allows us to observe their strategy for responding to such challenges. To see the problem, consider the (constructed) sentences in (1), which are among the more frequently used examples in the relevant literature.

(1) a. The stove is hot

b. Liz has not eaten breakfast yet 
For both (1a) and (1b), the context in which they may be uttered affects the criteria for determining their truth or falsity. At a temperature of $140^{\circ} \mathrm{C}$, a stove would not be considered hot, and so (1a) would be false, if you plan to bake bread in it, but (1a) would be deemed true if you are wondering whether it is safe to touch the stove with your bare hands (Travis 1996). And as for (1b), a literal interpretation should have assigned it the meaning that Liz has never had breakfast, even though any reasonable person would understand (1b) as stating Liz has had no breakfast on the day on which it was uttered. These examples show that we cannot exclude persons, with their rich understanding of the situations in which utterances are made, from an account of linguistic meaning, even if meaning is construed in the traditional logicist terms of truth conditions.

To understand how "hardline" adherents of the logical approach respond to this critique, we should bear in mind that the Aristotelian conceptualization of language, as such, is viewed by these scholars not as a model to defend, but as a self-obvious ground for any discussion of language and semantics. They then defend their truth-based semantic theories from this self-evident ground.

This is the basis for the sharp analytical distinction between semantics and pragmatics (and its close correlates, the distinctions between meaning and use and the literal and figurative), which forms the latest line of defense for formal and truth-based semantic theories against the onslaught of evidence 
that appears to falsify them. The basic idea here is that the true meaning (or rather "semantic content") of a sentence is given in its literal interpretation, arrived at by composing the literal meanings of the words making it up according to the sentence's syntactic structure. This semantic content is then elaborated upon, mostly through drawing conversational implicatures (Grice 1989) from it.

It has long been acknowledged that the "semantic content" of a sentence need not form a complete proposition (Bach 1994), or make sense on its own (e.g., Cappelen and Lepore 2005), but its existence has been treated as if it were a self-evident, undeniable truth. That the semantic content of a sentence, thus determined, bears little or no relation to what we would normally take this sentence to mean is said to have no "significance for truth conditional semantics" (Cappelen and Lepore 2005, p. 47). Taking people's actual use and understanding of language as a relevant starting point for discussing semantics is claimed to involve a "pragmatic fallacy" (Salmon 1991).

So, on this view, we can say (1a) is true if and only if the stove is hot, and this statement of the sentence's truth conditions would be correct regardless of what exact temperature "hot" implies, and a semantic interpretation of (1b) would yield the statement that Liz has never eaten breakfast in her life. We can use (1b) to say Liz has not yet had breakfast today, but this is merely an implicature we draw from it (Bach 2005). 
This line of defense works reasonably well with the sort of critiques cognitive linguists have levelled against logicist accounts of semantics (at least when evaluated on the logicists' terms), and it may appear at first blush that the same strategy would apply to examples of fictive interaction too. Thus, if a speaker refers to dots that scream "Do something now about me" (example analyzed in Oakley and Coulson 2008), we can safely claim the semantic content of that speaker's sentence has dots (in the literal sense) screaming (in the literal sense) the exact words "Do something now about me", and whatever else one gathers from this sentence is already a matter of how it was used, of its pragmatics. ${ }^{1}$

Alas, if we probe a bit further into the fictive interaction field, we will find a class of examples with which even this defense strategy fails. I specifically refer to direct speech compounds (Pascual, Królak, \& Janssen 2013; Pascual 2014, pp. 59-81), as seen in (2):

(2) a. How are you? Fine. Relationships (Pascual 2014, p. 67)

b. touch-your-nose-and-stand-on-one-foot,-are-you-drunk? test (p. 63)

c. "if only I had this or that [...] then I'd be happy" attitude (p. 68)

${ }^{1}$ Of course, dots cannot scream, but this is hardly a problem. The literallyinterpreted semantic content amounts to a patently false claim about screaming dots. This flouts Grice's (1989) maxim of quality, at which point conversational implicature, and thus pragmatics, kicks in. 
d. Make-your-kids-into-greedy-little-materialistic-consumptionaddicts day (p. 70)

These are all attested examples of actual linguistic usage, instantiating a widespread practice, but this fact is of little consequence in the eyes of logically-minded semanticists. ${ }^{2}$ Instead, these semanticists would surely notice that neither of the examples in (2) makes up a full sentence. But this can easily be fixed:

(3) a. Stephen and Matilda have a "How are you? Fine." relationship.

b. The cop gave John the touch-your-nose-and-stand-on-one-foot,are-you-drunk? test.

c. The "if only I had this or that then I'd be happy" attitude does not help you in life.

d. Tomorrow is Make-your-kids-into-greedy-little-materialisticconsumption-addicts day.

Syntactically, the sentences in (3) can either be declared ungrammatical (and therefore, on the logical account, meaningless), or we

2 "Ordinary discourse often involves the use of complex expressions which would be counted as ungrammatical even by the utterer's own lights [...] It is absurd to suppose that we should count such discourse as grammatical, and thereby modify syntactic theory to account for it, and this despite its (statistically speaking) relative normalcy. It is just as absurd to suppose that our conception of semantics should be modified to account for every communicative action which involves the use of language" (Stanley 2000, p. 408). 
can analyze the entire fictive utterance as a single constituent (Pascual 2006). The sentences in (3) appear to bear meaning, also in the narrow sense of having well-defined truth conditions. Thus, we can tell whether (3a) is true or false by observing whether or not Stephen and Matilda's relationship indeed fits the description. So it would be difficult even for adherents of the logical approach to declare such sentences meaningless.

However, if deemed meaningful, the sentences in (3) pose a serious problem for a logical approach. Each direct speech modifier in (3) contains within it at least one (fictive) utterance — and utterances come with all of their attendant pragmatics. We cannot correctly understand (3a) unless we identify "How are you? Fine" as a question-answer pair, and as an exchange of greetings. Moreover, the pragmatics in question is of the most unruly type (from the logicist perspective); it links not to the current context of utterance, but to the typical or fictive context of the embedded utterance: "I" in (3c) does not refer to the current speaker and "you" or "your" in (3a) and (3b) does not refer to the current addressee.

The problem is that the methods, explained above, of separating pragmatics out of a sentence's semantic content no longer work. Direct speech compounds need not use figurative language. Thus, in (3b), all the words in the compound ("touch", "nose", "stand", “one”, “foot”, “drunk") mean exactly what the dictionary says they mean. Crucially, it is also impossible to account for the examples in (3) as implicatures. The criterion for identifying an implicature is cancellability. (3d) is particularly instructive 
in this sense. Consider: "Tomorrow is make-your-kids-into-greedy-littlematerialistic-consumption-addicts day, and I don't mean Christmas". Originally, (2d) referred to Christmas day, but this reference can be denied. This is a typical case of "cancelling" an implicature. But what is the "literal" meaning to which our understanding of this sentence reverts after cancellation? We'd still expect the utterer to have referred to a day (and behaviors taking place on it) characterized by greed, addictive consumption, etc. What is cancelled is the reference to a specific holiday, but not the meaning of the reported speech compound. ${ }^{3}$

What I hope to have shown in this brief discussion is that it is impossible to build a wall separating semantics from pragmatics, linguistic meaning from the way people act, think, and understand each other.

\section{The monological approach to language}

[M]eaning is, in the last analysis, a matter of conceptualization (what else could it possibly be?)

(Langacker 1987, p. 156)

${ }^{3}$ Note also that direct speech compounds do no function (semantically) as simple reported speech. Thus, (3c) does not attribute the uttering of the words "if only I had this or that then I'd be happy" to anyone. It is also not a self-referential statement about these words as such (despite De Brabanter 2005; see Pascual 2014, pp. 74-75). 
A monological approach to language seeks explanations for linguistic phenomena in the individual human mind. If logical approaches to language have to peg meaning to objects in the world and their properties, monological views are free to recognize the dynamic and contextual nature of meaning, reflecting the dynamic and contextual nature of human perception and cognition.

Historically, monological approaches to language, in their purest form, flourished in $19^{\text {th }}$ - and early $20^{\text {th }}$-century German linguistics (see Voloshinov 1986, pp. 48-52, 83-98 for a critical overview). In this original form, monologism was typically aligned with idealist trends in philosophy: meaning, grammatical phenomena, and especially linguistic change, were accounted for as instantiations of the internal development processes of the collective national, or even universal (Absolute) mind or spirit (see, e.g., Vossler 1932). More recently, a new version of monologism has emerged within Cognitive Linguistics. This new monologism focuses on the cognitive capacities of the individual human mind, particularly on conceptualization, to account for linguistic meaning and linguistic phenomena (an emphasis reflected in the motto I used for this section). Typically monological themes in Cognitive Linguistics include, among others, work on metaphor (Lakoff and Johnson 1980) and conceptual integration (Fauconnier and Turner, 2002) as features of human cognition that shape language, the introduction of radial categories with their prototype-periphery structure into linguistics 
(Langacker, 1987), following work on prototypes in cognitive psychology (Rosch 1973), and the notion of fictivity (Talmy 2000), linked to our cognitive capacity of imagination.

Cognitive Linguistics as such, however, is not reducible to monologism alone. Instead, Cognitive-Linguistic theories typically combine monological and dialogical principles and motivations. Thus, a clear commitment to a usage-based account of meaning and of grammatical form (Langacker 1987; Croft 2001) is a core dialogical element of Cognitive Linguistics. In recent years, there has been an increasing trend toward dialogism and intersubjectivity in the field (e.g., Croft 2009; Dancygier and Sweetser 2012; Du Bois, 2014; Oakley and Hougaard, 2008; Verhagen, 2005) - a trend which the literature on fictive interaction is very much part of. In this context, it is also important to frame my argument in the present chapter correctly, not as an argument against Cognitive Linguistics, but rather as an argument internal to it, an argument for a more consistently dialogical approach within Cognitive Linguistics.

From a dialogical perspective, a critique of monological approaches differs both in its aims and in its methods from a critique of logical ones. Logical theories of language and meaning are, on a dialogical view, fundamentally wrong about how language works. A dialogical critique of such theories would seek to refute them. By contrast, a dialogical critique of monological theories does not come in the form of a refutation. After all, dialogue occurs between individuals, so a proper account of what goes on in 
a single person's mind when speaking and communicating is part and parcel of any correct description of dialogue. Hence, the qualm dialogism has with consistently monological accounts of language is not that they are wrong, but that they are incomplete. Monological accounts of linguistic phenomena are compatible with dialogical accounts (e.g., there is nothing about metaphor, or about the prototype-periphery structure of categories, not to mention fictivity, that would not fit comfortably into a dialogical account of language), but with many phenomena, including most forms of fictive interaction, it is only the dialogical position that can account for the motivation behind the linguistic phenomenon itself. When our picture of language involves one mind facing the world around it, we may be able to offer a good explanation for what is going on in fictive interaction, but not an account for why would one use it. Fictive interaction, as I shall argue, would be gratuitous in a linguistic world designed for a single mind, unless this mind is itself already dialogic, already shaped from within by interaction with other minds.

As a first illustration, consider the sentences in (4):

(4) a. Something tells me I'm into something good.

b. I'm not myself today (Lakoff and Johnson 1999, p. 283).

Apart from being the title of the Herman's Hermits oldie, (4a) is one of many examples (Pang 2005; Pascual 2014 pp. 91-98) of fictive interaction used to express the thoughts or feelings of an individual by conceptually 
splitting that individual into two or more speakers (in this case, "something" is a speaker that addresses "me"). Now, splitting of the self has been dealt with extensively in cognitive linguistics. There is the detailed study of conceptual metaphors involved in such expressions by Lakoff and Johnson (1999, pp. 267-289) and there is the even earlier treatment of the subject as part of Mental Space Theory (Fauconnier 1994; Lakoff and Sweetser 1994, pp. ix $-\mathrm{x})$. These studies and others provide an account for the meaning of such expressions as (4b), which pose a severe challenge to logical approaches (note the contradiction that emerges if we assign the deictics "I" and "today" their standard functions, as done by Kaplan 1989).

But then there is also the question of motivation, of why do people use such expressions as in (4). And I don't mean local pragmatic and conversational reasons, as important as these are. "Something tells me" is a commonly used turn of phrase that people find fitting, eloquent, functional, accurate, in a variety of situations. How come? Why do such expressions serve our local purposes successfully? Viewed from this angle, (4a) and (4b) differ substantially. By uttering (4b), the speaker compresses a multiplicity of behaviors and attitudes she has exhibited in a wide variety of situations, at different places and times, into one compact image (a self, as distinct from the subject, in Lakoff and Johnson's (1999) terms), and then goes on to contrast her behavior today with this identity. This fits well into a monological account, where a conceptualizer uses a single image to mentally access a complex distribution of diverse phenomena. In their discussion of 
"constitutive and governing principles" for conceptual integration, Fauconnier and Turner (2002, pp. 309-352) provide exactly this sort of monological rationale. Of particular interest is one important principle (or "noteworthy subgoal") they list: "Go from Many to One" (p. 323). Indeed, in (4b), the speaker goes from many behaviors and attitudes to one self.

However, this is not the case in (4a). Consider a possible paraphrase: "I expect something good to happen to me". Compared with this paraphrase, (4a) does not seem to help us grasp anything that should be particularly difficult for the speaker's mind to access. Quite to the contrary (and this is typical of the fictive-interaction kind of self-splitting), what (4a) expresses is the speaker's current state of mind, to which she (presumably) has direct mental access. Nevertheless, this state of mind is conceptualized and presented in (4a) as a (fictive) conversation with two participants. ${ }^{4}$

Faced with a different, but in some ways similar challenge to their theory posed by examples of fictive motion, Fauconnier and Turner (2002, pp. 378-379) write:

${ }^{4}$ The paraphrase I used is not entirely accurate: "something tells me" reflects less certainty than "I expect", differs slightly in its evidential status. But this is, again, very typical. Fictive interaction allows one to mentally access and to express subtle shades of one's own emotion and attitude that our standard vocabulary of terms for inner states does not fully cover. This further underlines the dialogical nature of people's subjective experience. 
Human action [...] is a basic human-scale structure. [...] The blended space, with action, event, and state, is more complex from a formal point of view than the input with just a state, but the added complexity crucially enhances the human-scale quality of the scene. It is more congenial for human beings to process a full, dynamic, intentional human-scale action than it is to process one apparently simple component of it.

Now, replace the word "action" in this quote with "interaction"—-and the resulting concession would provide a good account of the fictiveinteraction type of splitting the self, supplementing the subgoal "go from many to one" with the new subgoal, "go from one to two". But then, accepting that interaction is essential to what human scale is, that human cognition can access a dialogue between several agents better than a solitary inner state, amounts to replacing a monological theory with a dialogical one.

To further explore some of the issues at stake, consider another quote from the same book:

(5) [B]uilding a rich emergent structure out of a tenuous connection between inputs is a deep principle of science. The connection between an apple and the moon seems at first blush to be only the most tenuous analogy of shape and some motion, but in the blend of Newtonian physics, the apple and the moon are the same and exemplify the laws of the universe. Similarly, the psychoanalyst searches for seemingly "accidental" identities and analogies running across childhood experience, dreams, and adult behavior ("You say you always wear red shoes to the circus. What was the color of your hat, did you say, when you visited your grandmother on her deathbed? You said the circus was a 'celebration of life'. Of course, 
you mean 'of death"') (Fauconnier and Turner 2002, pp. 136-137, italics added).

The italicized words are an example of fictive interaction. Like the other examples I will present below, it is also an instance of what Mikhail Bakhtin (1984, pp. 181-210) called "double-voiced discourse"-an utterance in which we can hear two different voices, two different subjects' positions, expressed simultaneously in the very same words (by definition, doublevoiced discourse always involves fictive interaction). This example exhibits three starkly dialogical features that I would like to focus on here:

1. The psychoanalyst's voice is relevant in the context of a discussion of the discipline, not the person. A space is available for this character to speak in. 2. The psychoanalyst's voice becomes the object of evaluation by the authors, of dialogical stance (Du Bois 2007) toward it.

3. The psychoanalyst's voice is not merely described or represented, but is dramatically enacted by the authors.

All three features can be illustrated if we compare the actual quote above with an alternative formulation (a substitute for the italicized parenthetical remark) that was not used:

(6) $[\ldots]$ For instance, the psychoanalyst may link between the fact that a patient reports always wearing red shoes to the circus and the color of that patient's hat when he visited his grandmother on her deathbed and interpret the patient's statement that the circus is "a 
celebration of life" as reflecting a connection, in his psyche, between the circus and death.

Let us begin with the first feature. The fact that the psychoanalyst-a person-shows up, rather than psychoanalysis as a discipline in the context of Fauconnier and Turner's discussion there is notable, but we can give this fact a purely monological account by analyzing this as a case of metonymy. However, the psychoanalyst also begins to speak.

In terms of conceptualization, (5) and (6) give the reader essentially the same information. Indeed, if anything, (6) offers a clearer and more explicit (though perhaps slightly less compact) statement of how psychoanalysis exemplifies the principle Fauconnier and Turner (2002) are discussing. Fictively "quoting" the psychoanalyst appears unmotivated. And yet, I think any reasonable reader would agree the use of fictive interaction in (5) is a much livelier choice of wording than the dull paraphrase in (6). If meaning is a matter of (monological) conceptualization, both original and paraphrase should be equivalent in what they mean, and yet there is a noticeable difference between (5) and (6) that the use of fictive interaction seems to introduce.

One such difference is that the psychoanalyst in (5) is not merely quoted; she is ridiculed. This ridicule is not conveyed in (6), even though we are given the same information about the psychoanalyst's reasoning that 
makes it sound ridiculous in (5). ${ }^{5}$ This ridicule is an important (if secondary) aspect of what the text in (5) means. Note also that such ridicule is not an external pragmatic add-on to the conceptual structure. Consider another example of fictive interaction from the same book (Fauconnier and Turner 2002, p. 175 italics added):

(7) As Darwin noted, evolution's main trick seems to be gradual change, so an adaptationist account is obliged to show that each step would have been adaptive. Evolution is never allowed to think "Well, if I could get to stage ten, it would be good, so give me a break while I go through the first nine".

Here, the same type of ridicule we saw directed at the psychoanalyst is directed at evolution (or, indirectly, at an adversary's views about evolution), only now the ridicule itself is "embedded" in the conceptual structure (in a counterfactual space).

What the use of fictive interaction enables here is the reading of the psychoanalyst's (or evolution's) words as parody. In parody, we must have

${ }^{5}$ Of course, I am not saying the use of fictive interaction is a conditioneither necessary or sufficient—-for conveying ridicule. In this instance, one important reason that (6) does not convey ridicule is that the context (exemplifying "a deep principle in science", with Newtonian physics as another case in point) actively discourages such a reading. A different context may have enabled ridicule to pass through. But then, the same context is not enough to block the reading of the fictive interaction sequence in (5) as a parody. 
the psychoanalyst's voice heard, so that it can be the vehicle for the authors' parodying ridicule. Conversely, once a voice is heard, the authors' stance toward this voice and the speaker to whom it belongs becomes relevant to the interpretation of the passage.

As noted above, the example in (5)—and parody in general—belongs to the class of phenomena Bakhtin (1984, pp. 181-210) called "double-voiced discourse". In Bakhtin's analysis, double-voice discourse involves a dialogic relation between author and character. So, in our case, we have not only the represented dialogue between psychoanalyst and patient and the framing dialogue between Fauconnier and Turner and their readers, but also a dialogue between Fauconnier and Turner and the psychoanalyst. The ridicule we hear directed toward at least some psychoanalytic practices in the analyzed quote belongs to this latter level of dialogue.

But let us come back to the third dialogical feature of the psychoanalyst example: its performative or dramatic aspect. The paraphrase in (6) speaks about the psychoanalyst, but in (5) Fauconnier and Turner actually impersonate the psychoanalyst, assume her role (this is, in a sense, the speaker-perspective side of a point already made above). To give you an impression of some of the complexity dramatic role-play can exhibit in even quite mundane situations, consider the conversation transcript in (8): ${ }^{6}$

${ }^{6}$ The original conversation was recorded by the author and conducted in Hebrew; the transcript below is a translation, in simplified notation (which is 
(8) $1 \mathrm{~s}$ : Can we help with anything?

2 R: No but it's time to sit down cause the food is getting cold it's a cold day today.

$3 \mathrm{~s}: \downarrow$ Oy $[(\mathrm{h})(\mathrm{h})(\mathrm{h})$ [if we don't eat up we won't grow up?

$4 \mathrm{R}:$ [the [the good thing is that

$5 \quad(0.5)$

6 R: Exactly. (.) the good thing is that I'm sitting alone.

A few words on what is going on in this conversation. First of all, $\mathrm{R}$ is the host of a small family gathering. Her guests are her two adult children (both in another room when this conversation takes place), and her son-inlaw (S). As the conversation begins, $\mathrm{R}$ is about to finish arranging the dishes on the dinner table for the meal.

On one level, what we see in (8) is S politely asking whether he could help R in serving the meal and R telling him to go get the other diners to come to the table instead. But there's also another level. To understand what's going on at that other level, I need to say a few words about a cultural stereotype that plays an important role in this conversation. English speakers might be

sufficient for present purposes). See Sandler (2009) for a detailed analysis of the original. Transcription symbols used follow Jefferson (2004). 
familiar with this stereotype under the label "Jewish Mother". ${ }^{7}$ The Jewish Mother is an overweening parent, who gets her children (typically adults, or at least adolescents) to do what she wants by means of constant guilt-tripping wrapped in bitter irony. The Jewish Mother comes with a repertoire of utterances and behaviors, and a good amount of folklore (jokes, stories). This repertoire is on display in the conversation we are looking at: "The food is getting cold", "If you don't eat up you won't grow up", and, perhaps the most famous one (among Hebrew speakers): "[leave me] sitting alone in the dark" are all stereotypical Jewish-Mother utterances that are either repeated or alluded to here.

What we see in this conversation then is $\mathrm{R}$ adding a touch of humor to her request of $\mathrm{S}$ in line 2 by uttering it in the Jewish Mother's voice. In line $3, \mathrm{~S}$ actually profiles the dramatic aspect of R's previous turn by joining the role-play (as the Jewish Mother's ill-fated child). In terms of conceptual content, both the fictive and the factive readings of R's utterance point to it being a request to call everyone else to the dinner table, but $\mathrm{S}$ nevertheless responds to the dramatic aspect of R's words as such. Note also the rising intonation contour at the end of line 3. In this instance, it marks the utterance as a guess. $\mathrm{S}$ is guessing the Jewish Mother role-play is on purpose, but asks

${ }^{7}$ Hebrew speakers would refer to it as the "Polish Mother", with a middleaged Ashkenazi-Jewish woman as a prototype in both cases. $\mathrm{R}$ - it should be notedfits the stereotype in terms of ethnic identity and age. 
for confirmation (and does so, again, by joining in the role-play, not by making an explicit query). R's eventual response in line 6 starts with giving the confirmation asked for ("Exactly"), followed by what is essentially a repeat of the request in line 2. But this is again done in the Jewish Mother's voice ("The good thing is that I'm sitting alone"_-"sitting alone" here simultaneously refers to the predicted undesirable situation of $\mathrm{R}$, the host, sitting alone at the dinner table while her guests are busy doing other things, and alludes to the Jewish Mother sitting alone in the dark, offended by her uncaring and ungrateful children). Following this, $\mathrm{S}$ (or is it the scolded, guilttripped child of the Jewish Mother?) goes to the other room to call the other guests to dinner.

At no point during the entire exchange does either participant step out of character. Fictively impersonating the Jewish Mother and her child is seamlessly woven into the more practical exchange about calling guests to the dinner table. Fictive utterances that are part of the role-play are used to successfully accomplish (speech) acts that are part of the practical exchange.

Now, Blending Theory can and does provide an account of situations in which people act out roles, as in, among others, the brief discussion of dramatic blends (Fauconnier and Turner 2002, pp. 266-267), of "living in the blend" (pp. 83-84), and of a variety of rituals (e.g., pp. 85-86). There is, however, a subtle but crucial issue to take into account here. It has to do with the distinction between the actor's and analyst's (and observer's) different points of view. In the cases Fauconnier and Turner discuss, the significance 
of this distinction is somewhat masked by the fact that the conceptual integration network is given to the actors in advance. The Jewish Mother example, however, can help put the issue at stake in sharper relief.

Blending Theory provides an insightful account of what is going on in (8) from the analyst's perspective: $\mathrm{R}$ and $\mathrm{S}$ and the situation in which they interact are blended with the stereotypical Jewish Mother and child scenario. If we apply Blending Theory here for such analytical or descriptive purposes, it does its job perfectly well. The problem arises if we try to go one (monological) step further, and claim blending to be the cognitive operation that underlies the observed role-play, that is, to use blending to reduce dialogue to individual cognition (this appears to be the project pursued by Pagán-Canóvas and Turner, this volume). In this case, the analyst's perspective is no longer enough, and we would need to claim the role play $\mathrm{R}$ and $\mathrm{S}$ engage in instantiates a blending operation from their own, actors', perspective. This, in turn, would mean the current communicative ground serves as an input in the blending operation going on in the minds of its participants (again, see Pagán-Canóvas and Turner, this volume, who make this claim explicitly about most cases of fictive interaction, or "fictive communication", to use their own term).

However, for the current communicative ground to be available to me as an input, I need to stand in a position in space and time that is external to that ground. As Bakhtin (1990) emphasized long ago, this is strictly impossible. I do have a perspective on the ongoing interaction, which is 
available to me as an input, but this perspective does not include my own active position. The only way I can gain mental access to my current role in the communicative ground is through its reflection in my interlocutor's responses to my utterances. $\mathrm{R}$ and $\mathrm{S}$, in our transcript, cannot jump out of their skins and perceive their performance. They also cannot tell how the conversation will be unfolding in advance. In line $2, \mathrm{R}$ does not yet know what S's answer to her turn of talk is going to be (see Oakley and Hougaard 2008, and especially Cienki 2008, for a discussion of closely related issues). In line 2 , as yet, there is nothing that can be blended with the interaction between Jewish Mother and child, which would be available to R and S as an input. Rather, this input is in the process of being created by $\mathrm{R}$ and $\mathrm{S}$, and an impromptu enactment of the Jewish Mother and her child is being created. In short, it is not the blending that produces the role play here, but the role play that produces the blending, not in the solitude of an individual mind, but through on-line negotiation in dialogue between two.

As I hope the discussion here has shown, intersubjectivity in the way people speak and think, as instantiated by the many forms of fictive interaction, cannot be fully reduced to the terms of individual cognition (let alone to abstract logical notions), unless we acknowledge individual cognition itself is in many important respects already dialogical. In the remainder of this chapter, I would like to outline some of the consequences of approaching meaning from the dialogical side, that is, of taking dialogue 
and intersubjectivity as the starting point for an account of meaning in language.

\section{The dialogical approach to language}

By meanings I understand answers to questions. That which answers no question is meaningless to us [...] Meaning is potentially infinite, but it may only be actualized when it comes into contact with other meaning.

(Bakhtin 1986, pp. 145-146, translation modified)

A dialogical approach to language sees interaction as an essential aspect of language and meaning on all levels of description. On a dialogical account, the conversation frame is not merely $a$ frame; it is the Mother Frame. That is, we always assume by default that there is (fictive) interaction between voices going on in anything people utter. Sometimes this level of analysis can be reduced to a simplified scenario, in which a speaker uses her authorial voice throughout but this is a special case. As a matter of course, we always ask ourselves at any point, "Who's talking?"; we always expect voices to appear, 
explicitly or implicitly. Like Bakhtin (1986, p. 169), we "hear voices in everything and dialogic relations among them". 8

The Bakhtin quote in the motto to this section offers what is in effect the overarching semantic principle of a dialogical account of language: the meaning of an utterance is reflected in how it is responded to. This principle has been independently applied by Harvey Sacks (1992) in Conversation Analysis: to understand what kind of an action a turn in conversation performs, what it is, what it means, we need to look at the turn or turns that respond to it (cf. Bilmes 1985).

But fictive interaction allows us to extend this principle, as Bakhtin indeed intended it to be, from the relation between utterances ${ }^{9}$ to the internal dialogue going on within utterances (thus, the meaning of the psychoanalyst's fictive utterance in (5) is only understood if we recognize the evaluation with which the authors respond to it). In this sense, dialogism offers a homogenous approach to language: the same principles that are in play when interpreting

${ }^{8} \mathrm{~A}$ related fact is that, on this level, human interaction takes place in a thoroughly personified, speaking, world, in which things, ideas, emotions, organizations, etc. can always acquire voice and agency (Cooren 2010; Cooren and Sandler 2014).

${ }^{9}$ I am using here the term "utterance" in Bakhtin's (1986, pp. 60-102) sense - a discursive whole delimited by the change of speaking subject. An utterance in this sense can be anything from the briefest turn in a conversation to a multivolume novel or treatise, but it is a single "work". 
the utterance in the context of the interaction it is part of are also in play when interpreting its internal (grammatical, conceptual, etc.) structure.

On a dialogical account of language, voices and interaction between them are everywhere. It's intersubjectivity all the way down. Words, phrases, prosodic markers, the very texture of language, are all imbued with voices. Thus, "the food is getting cold" is a phrase that carries the Jewish Mother's voice - among others-with it. It is only through these voices and our responding manipulation of them do they become meaningful (Bakhtin, 1981; Gasparov, 2010).

As I noted at the very outset, the conversation frame is a frame of intersubjectivity. Since in fictive interaction language and cognition are structured by the conversation frame, a dialogical account of such examples as I used in this paper is straightforward. The challenge for the dialogical approach to meaning is to show how the principles and ideas I briefly outlined here can apply more generally, even when the dialogue of voices in an utterance is not easily apparent. Several recent works have achieved substantial progress along this path. I should particularly note Verhagen's (2005) analysis of such ubiquitous constructions as (sentential) negation in explicitly intersubjective terms and Gasparov's (2010) theory of linguistic texture. Other significant contributions toward a dialogical theory of language and meaning include - among others — such programmatic works as Wold (1992), Linell (1998), Ducrot (1984), and (within Cognitive Linguistics proper) Croft (2009), Du Bois' (2014) work on resonance and implications 
drawn from it for grammar (Brône and Zima 2014), and, of course, Pascual's $(2002,2006,2014)$ work on fictive interaction and the research program it has generated (as represented in this volume). To this, one should add studies focusing on the central role of intersubjectivity in human cognition, such as Zlatev et al. (2008). ${ }^{10}$

All this progress notwithstanding, elaborating a full dialogical theory of meaning is still a task that lies ahead. This is not a task for a single paper, or for a single author's efforts, so I will stop here for now. But I do hope what I said so far makes a good case for developing such a dialogical approach further, and for the central place the study of the rich and diverse forms of fictive interaction has in such an endeavor.

\section{References}

Arens, H. (1984). Aristotle's theory of language and its tradition: Texts from 500 to 1750. Amsterdam: John Benjamins.

${ }^{10}$ The title and central metaphor of Zlatev et al. (2008), however, also gives reasons to pause and practice some philosophical caution. The notion of "the shared mind", if taken seriously, represents a step backwards from a dialogical point of view. Instead of offering an account of individual cognition grounded in intersubjectivity, it offers the long-forlorn specter of a collective mind, a single super-subject, which is as lonely in facing the outside world as the individual subject is on a strictly monological account. Erase the border (as thin and shifting as it may sometimes be) between self and other, and intersubjectivity evaporates with it. 
Bach, K. (1994). Conversational impliciture. Mind and Language, 9(2), 124-162. doi: 10.1111/j.1468-0017.1994.tb00220.x

Bach, K. (2005). Context ex machina. In Z. Gendler Szabó (Ed.), Semantics versus pragmatics (pp. 15-44). Oxford: Clarendon Press.

Bakhtin, M.M. (1981). Discourse in the novel. In The dialogic imagination: Four essays (pp. 259-422). Austin: University of Texas Press.

Bakhtin, M.M. (1984). Problems of Dostoevsky's Poetics. Minneapolis: University of Minnesota Press.

Bakhtin, M.M. (1986). Speech genres and other late essays. Austin: University of Texas Press.

Bakhtin, M.M. (1990). Author and hero in aesthetic activity. In Art and answerability: Early philosophical essays (pp. 4-256). Austin: University of Texas Press.

Barnes, J. (Ed.). (1984). The complete works of Aristotle: The revised Oxford translation (Vol. 1). Princeton, NJ: Princeton University Press.

Bilmes, J. (1985). "Why that now?" Two kinds of conversational meaning. Discourse Processes, 8, 319-355.

Brône, G., \& Zima, E. (2014). Towards a dialogic construction grammar: Ad hoc routines and resonance activation. Cognitive Linguistics, 25(3), 457-495. doi: $10.1515 / \operatorname{cog}-2014-0027$

Cappelen, H., \& Lepore, E. (2005). Radical and moderate pragmatics: Does meaning determine truth conditions? In Z. Gendler Szabó (Ed.), Semantics versus pragmatics (pp. 45-71). Oxford: Clarendon Press.

Cienki, A. (2008). Looking at analyses of mental spaces and blending / Looking at and experiencing discourse in interaction. In T. Oakley, \& A. Hougaard (Eds.), Mental spaces in discourse and interaction (pp. 235-245). Amsterdam: John Benjamins.

Cooren, F. (2010). Action and agency in dialogue. Amsterdam: John Benjamins.

Cooren, F., \& Sandler, S. (2014). Polyphony, ventriloquism, and constitution: In dialogue with Bakhtin. Communication Theory, 24, 225-244. DOI:10.1111/comt.12041

Croft, W. (2001). Radical construction grammar: Syntactic theory in typological perspective. Oxford: Oxford University Press. 
Croft, W. (2009). Toward a social cognitive linguistics. In V. Evans, \& S. Pourcel (Eds.), New directions in cognitive linguistics (pp. 395-420). Amsterdam: John Benjamins.

Dancygier, B., \& Sweetser, E. (2012). Viewpoint in language: A multimodal perspective. Cambridge: Cambridge University Press.

De Brabanter, P. (2005). The impact of autonymy on the lexicon. Word, 56(2), 171200.

Du Bois, J.W. (2007). The stance triangle. In R. Englebretson (Ed.), Stancetaking in discourse: Subjectivity, evaluation, interaction (pp. 139-182). Amsterdam: John Benjamins.

Du Bois, J.W. (2014). Towards a dialogic syntax. Cognitive Linguistics, 25(3), 359410. doi: $10.1515 / \operatorname{cog}-2014-0024$

Ducrot, O. (1984). Le dire et le dit. Paris: Minuit.

Fauconnier, G. (1990). Invisible meaning. Proceedings of the Berkeley Linguistics Society, 16, 390-404.

Fauconnier, G. (1994). Mental spaces: Aspects of meaning construction in natural language. Cambridge: Cambridge University Press.

Fauconnier, G., \& Turner, M. (1996). Blending as a central process of grammar. In A.E. Goldberg (Ed.), Conceptual structure, discourse and language (pp. 113-130). Stanford, CA: CSLI Publications.

Fauconnier, G., \& Turner, M. (1998). Conceptual integration networks. Cognitive Science, 22(2), 133-187. doi: 10.1016/S0364-0213(99)80038-X

Fauconnier, G., \& Turner, M. (2002). The way we think: Conceptual blending and the mind's hidden complexities. New York: Basic Books.

Gasparov, B. (2010). Speech, memory, and meaning: Intertextuality in everyday language. Berlin: De Gruyter.

Gendler Szabó, Z. (Ed.). 2005. Semantics versus pragmatics. Oxford: Clarendon Press.

Grice, H.P. (1989). Studies in the way of words. Cambridge, MA: Harvard University Press.

Hopper, P.J. (1998). Emergent grammar. In M. Tomasello (Ed.), The new psychology of language: Cognitive and functional approaches to language structure (pp. 155-175). Mahwah, NJ: Lawrence Erlbaum Associates. 
Jefferson, G. (2004). Glossary of transcript symbols with an introduction. In G.H. Lerner (Ed.), Conversation analysis: Studies from the first generation (pp. 13-31). Amsterdam: John Benjamins.

Kaplan, D. (1989). Demonstratives. In J. Almog, J. Perry, \& H. Wettstein (Eds.), Themes from Kaplan (pp. 481-563). Oxford: Oxford University Press.

Lakoff, G., \& Johnson, M. (1980). Metaphors we live by. Chicago: University of Chicago Press.

Lakoff, G., \& Johnson, M. (1999). Philosophy in the flesh: The embodied mind and its challenge to western thought. New York: Basic Books.

Lakoff, G., \& Sweetser, E. (1994). Foreword. In G. Fauconnier, Mental spaces: Aspects of meaning construction in natural language (pp. $\mathrm{ix}-\mathrm{xvi}$ ). Cambridge: Cambridge University Press.

Langacker, R.W. (1987). Foundations of cognitive grammar: Volume 1, Theoretical prerequisites. Stanford, CA: Stanford University Press.

Linell, P. (1998). Approaching dialogue: Talk, interaction and contexts in dialogical perspectives. Amsterdam: John Benjamins.

Oakley, T., \& Coulson, S. (2008). Connecting the dots: Mental spaces and metaphoric language in discourse. In T. Oakley, \& A. Hougaard (Eds.), Mental spaces in discourse and interaction (pp. 27-50). Amsterdam: John Benjamins.

Oakley, T., \& Hougaard, A. (Eds.). (2008). Mental spaces in discourse and interaction. Amsterdam: John Benjamins.

Ochs, E., Schegloff, E.A., \& Thompson, S.A. (Eds.). (1996). Interaction and grammar. Cambridge: Cambridge University Press.

Pang, K.-Y.S. (2005). 'This is the linguist in me speaking': Constructions for talking about the self talking. Functions of Language, 12(1), 1-38.

Pascual, E. (2002). Imaginary trialogues: Conceptual blending and fictive interaction in criminal courts. Utrecht: LOT Publications.

Pascual, E. (2006). Fictive interaction within the sentence: A communicative type of fictivity in grammar. Cognitive Linguistics, 17(2), 245-267. doi: 10.1515/COG.2006.006

Pascual, E. (2014). Fictive interaction: The conversation frame in thought, language, and discourse. Amsterdam: John Benjamins. 
Pascual, E., Królak, E., \& Janssen, Th.A.J.M. (2013). Direct speech compounds: Evoking socio-cultural scenarios through fictive interaction. Cognitive Linguistics, 24(2). doi: 10.1515/cog-2013-0011

Rosch, E.H. (1973). Natural categories. Cognitive Psychology, 4, 328-350.

Sacks, H. (1992). Lectures on conversation. Oxford: Blackwell.

Salmon, N. (1991). The pragmatic fallacy. Philosophical Studies, 63, 83-97.

Sandler, S. (2009). The dialogical approach in the philosophy of language. (unpublished doctoral dissertation). Ben-Gurion University, Beer Sheva, Israel.

Stanley, J. (2000). Context and logical form. Linguistics and Philosophy, 23(4), 391434. doi: 10.1023/A:1005599312747

Talmy, L. (2000). Toward a cognitive semantics: Concept structuring systems. Cambridge, MA: MIT Press.

Travis, C. (1996). Meaning's role in truth. Mind, 105(419), 451-466.

Verhagen, A. (2005). Constructions of intersubjectivity: Discourse, syntax, and cognition. Oxford: Oxford University Press.

Voloshinov, V.N. (1986). Marxism and the philosophy of language. Cambridge, MA: Harvard University Press.

Vossler, K. (1932). The spirit of language in civilization. London: Kegan Paul, Trench, Trubner \& Co.

Wold, A.H. (Ed.). (1992). The dialogical alternative: Towards a theory of language and mind. Oslo: Scandinavian University Press.

Zlatev, J., Racine, T.P., Sinha, C., \& Itkonen, E. (Eds.). (2008). The shared mind: Perspectives on intersubjectivity. Amsterdam: John Benjamins. 